\title{
Interdependence of red pepper prices on selected wholesale markets in Poland
}

\author{
W. Sobczak ${ }^{1}$, R. Zbyrowski², B. Borkowski ${ }^{1}$ and J. Gołębiewski ${ }^{1}$ \\ ${ }^{1}$ Warsaw University of Life Sciences, Institute of Economics and Finance, Warsaw, Poland \\ ${ }^{2}$ University of Warsaw, Faculty of Management, Warsaw, Poland
}

\section{Summary}

The aim of the study is to determine the price transmission between wholesale markets in Poland for red peppers. Empirical data include daily prices on selected five wholesale fruit and vegetable markets in Poland in 2011-2016. The research was carried out on the following wholesale markets: Warsaw, Poznań, Kalisz, Radom, and Sandomierz. Dynamic econometric method such as VAR model was used for the analysis. The research carried out using dynamic econometric methods has shown that despite the occurrence of significant variation in the level of red pepper prices in the examined markets, their interaction was observed. The estimated parameters of the VAR model for red pepper prices suggest that there was a dependency between prices on selected wholesale markets within the period 2011-2016. At the same time, the strength and direction of mutual price relations varied in individual cases. In addition, changes in the prices of red peppers in the examined market were more strongly affected by the change in its level from the previous day than the impact of prices from other markets.

\section{Keywords}

price transmission, Vector Autoregressive Models, Granger causality, wholesale market

\section{Introduction}

The analysis of the price relations of agricultural products between different markets is often used in assessing market performance. The right of a single price is the theoretical foundation of the price assessment of the effectiveness of markets in agribusiness in terms of the pace and strength of the transmission of price signals between different markets. The literature points to two widely accepted principles relating to regional price differentiation. The first points out that the price differences between the two regions (or markets), which trade with each other, should be equal to the cost of transport. The second emphasizes that price differences between two regions (or markets) that are not involved in such trading, should be less than or equal to transport costs (Tomek and Robinson, 2001). Direct application of these two principles in empirical research requires determining whether price differences between regions (markets) are larger, smaller or equal to transaction costs. From the point of view of price assessment of market efficiency, an interesting issue is the analysis of the period, after which price differences decrease or disappear. Its length depends on the price level of integration of given

\section{Significance of this study}

What is already known on this subject?

- In the case of spatial integration of markets, there is statistical dependence between time series of prices, the analysis of which allows to determine the degree of their integration.

\section{What are the new findings?}

- Changes in a given market were more strongly affected by changes in the price in the same market than by the price in other markets. The barrier in marketing infrastructure or long distance between markets can affect the lack of integration.

What is the expected impact on horticulture?

- Based on the findings, some recommendations can be made to improve the red pepper marketing chain in Poland and in countries with a similar distribution system.

markets, which can consequently be treated as a criterion of price efficiency of markets in spatial terms. Monke and Petzel (1984) define an integrated market as a "market where prices are independent". In worldwide literature, this regularity is defined as spatial market integration (Fackler and Goodwin, 2001).

In the case of spatial integration of markets, there is a certain type of statistical dependence between time series of prices, the analysis of which allows to determine the degree of price integration of markets. As it is emphasized in the literature on the price-effective market, market (price) variables shape production, consumption and marketing (Kohls and Uhl, 1998). This also applies to agricultural markets, including the market for horticultural products. It should be noted that the agricultural products market is subordinated to the universal laws of a market economy, whereby it is characterized by specific features. It is necessary to aggregate them with a wide variety in terms of the quality and durability of products, tolerances for transport, as well as the rules for preparing goods for sale. These features in many cases cause different price behavior compared to other markets. Very often, the information asymmetry phenomenon occurs on agricultural markets. Disruptions in the transmission of price information between individual markets result in wrong decisions regarding the place of sale of products and thus affect the economic performance of agricultural holdings (Gołębiewski and Sobczak, 2017).

This study addresses the problem of assessing the interdependence of red pepper prices on the main wholesale 
fruit and vegetable wholesale markets in Poland. Wholesale markets are an important element of the institutional fruits and vegetables market infrastructure. The name wholesale markets of fruit and vegetables refers to the network of entities that organises trade in agricultural and grocery, as well as horticultural products. These entities were established in Poland after 1990 as part of governmental and non-governmental activities related to strengthening the agricultural market infrastructure and adapting it to the requirements of fragmented agriculture ${ }^{1}$. By concentrating supply and demand, these markets affect the growth of competitiveness, reduction in the number of intermediation agents in trade, price stabilization and improvement in the quality of products offered.

The subject of the analysis are the prices of red pepper. In Poland, the production of pepper is an important segment of the vegetable sector. In the structure of cover growing crops, it occupies the third position after tomatoes and cucumbers. Pepper production in Poland is strongly regionally concentrated. The main production centers are located in the vicinity of Radom and Kraków. A significant fluctuation in the level of prices in both time and spatial cross-section leads to the occurrence of asymmetries in price transmission and the lack of spatial integration. It should be noted that measuring the integration of wholesale markets can become one of the tools used to understand their functioning. And thus help manufacturers make decisions about where to sell their products. Due to the importance of this species in the Polish production of vegetables by the sub-curtains and the occurring price fluctuation, it was decided to take up this subject in order to learn the relationship in the formation of red sweet pepper prices on selected wholesale markets in Poland.

The main objective of the research was to assess the correlation of prices of red peppers on the fruit and vegetable wholesales markets in Poland. To this end, it was necessary to analyse the volatility and interdependence of prices in the examined markets using dynamic econometric models. The following research hypotheses were formulated in the paper: the first hypothesis indicates that Warsaw Agricultural-Food Wholesale Market in Bronisze have a dominant role in shaping fruit and vegetable prices on other wholesale markets. The second, however, is that wholesale markets for fruit and vegetables in Poland are spatially integrated.

\section{Materials and methods}

In order to determine the correlation of prices of red peppers on selected fruits and vegetables wholesale markets, quotations from five wholesale markets were used, i.e., Warsaw, Poznań, Radom, Kalisz, and Sandomierz ${ }^{2}$. Targeted selection of markets was made based on factors such as the size, scope and nature of the market. The selection also took into account the availability and comparability of data in the field of price quotations. Trading on most wholesale markets takes place seven days a week, 24 hours, dayly (with a technical break of several hours). The quotations concerned the domestic prices of red pepper. The time range of the studies covered the years 2011-2016. The analysis uses the series created by the daily price quotations during the season avail- ability of domestic sweet pepper. The total number of observations was 1,570, i.e., 314 observations per one wholesale market (annually the same period of time). The quotations concerned prices of red peppers grown under high covers. It should be noted that the prices quoted were prices declared by the producers as offer prices. Due to the lack of transaction monitoring on wholesale markets, due to the nature of these entities, it was impossible to obtain transaction price quotations. In order to verify hypotheses, the data used in the study regarding the red sweet pepper price level were obtained directly from the examined wholesale markets and the Polish Wholesale Markets Association.

Econometric methods have been used to determine the correlation of red pepper prices on wholesale markets. In order to examine the stationarity of the time series, the following tests were used: an extended Dickey-Fuller test (ADF, Augmented Dickey-Fuller test). The ADF stationarity test is recommended for examination time series with autocorrelated errors in the random walk equation. The ADF test uses the auxiliary regression model in the form of:

$$
\Delta y_{t}=\delta y_{t-1}+\sum_{i=1}^{k} \gamma_{i} \Delta y_{t-1}+\varepsilon_{t}
$$

where: $\delta$ and $\gamma$ - parameters estimated using the least squares method, $k$ - number of delays, $\Delta \mathrm{y}_{\mathrm{t}-1}$ - value in the series of the first differences within the period $t_{i}, \varepsilon_{t}-$ random component (Maddala, 2008). The null hypothesis for this test says that the series $y_{t}$ is non-stationary due to the occurrence of a unit root, while the alternative hypothesis indicates that the series is stationary.

For the analysis of causal relationships between the analysed variables, causality in the Granger sense was used, which determines whether one variable is the cause of another variable. According to the above, the variable $x$ is the cause in the Granger sense of the variable $y$ in case when the values of variable $y$ can be more accurately predicted by taking into account the past value of $x$ rather than taking these values into account. The equations of the VAR model are then used to test the causality in the Granger sense. With reference to the first VAR equation ( $i=1)$, that is

$$
x_{1 t}=\beta_{1 o}+\sum_{i=1}^{k} \sum_{j=1}^{p} \beta_{i j} x_{i t-j}+e_{1 t},
$$

the rejection of the null hypothesis

$$
H_{0}: \beta_{i j}=0 \text {, }
$$

for $\mathrm{I}=2$ a and a given lag $\mathrm{j}$, suggests that $x_{2}$ is a useful predictor of $x_{1}\left(x_{2}\right.$ is the cause of $x_{1}$ in the Granger sense).

Price volatility is analysed on many levels; in most cases these are changes in price levels in a given time interval on different markets. To this end, dynamic econometric models are used. The model is a causal model that takes into account the dynamic structure of each explained and explanatory process (Borkowski and Krawiec, 2009). In order to determine the variability of price levels in the indicated time interval on different markets, the dynamic econometric model

\footnotetext{
${ }^{1}$ In Poland in 2017 there were 29 wholesale markets, including 5 supraregional, 9 regional and 15 defined as local, characterized by a concentrated construction (Gołębiewski and Sobczak, 2017).

2 The data was recorded on the following markets: Warsaw - Warsaw Agricultural-Food Wholesale Market; Poznań Wielkopolska Gilda Rolno-Ogrodnicza S.A.; Kalisz - Rolno-Spożywczy Rynek Hurtowy Giełda Kaliska Sp. z o.o.; Radom - RolnoSpożywczy Rynek Hurtowy S.A. w Radomiu oraz; Sandomierz - Sandomierski Ogrodniczy Rynek Hurtowy S.A.
} 
- Vector Autoregression Model - VAR is used, which does not have a division into endogenous and exogenous variables. All variables in this model are explanatory variables, and their delays are explanatory variables. This model is a multi-equation model with an autoregressive structure. The VAR model is an alternative to the classical multi-equation model with interdependent equations. The specification of the $\operatorname{VAR}(\mathrm{p})$ model (where $\mathrm{p}$ is the maximum lag for the $k$ time series) can be written as:

$$
x_{i t}=\beta_{i o}+\sum_{i=1}^{k} \sum_{j=1}^{p} \beta_{i j} x_{i t-j}+e_{i t}, \quad i=1, \ldots, k
$$

where: $X_{\mathrm{t}}=\left[\begin{array}{lll}x_{1 t} & \ldots & x_{k t}\end{array}\right]^{T}-$ observation vector on the current values of all explanatory variables, $\beta_{i j}$ - matrix of parameters with delayed variables of the vector $X_{t}$ (excluding null elements), $k$ - model row, defining the maximum length of delay, $e_{t}=\left[e_{1 t} \ldots e_{k t}\right]^{T}-$ stationary random interference vectors (vectors of model equation residuals [Sims, 1980]).

\section{Results and discussion}

Peppers are an important species of vegetables produced in the world, whose global production has been showing a steady upward trend for many years. In the last five years, global sweet pepper harvest ranged from 44 to 50 million tons. The largest producers of this vegetable include China, Mexico, Turkey, Indonesia, USA and Spain. In the European Union, Spain is the largest producer of sweet peppers. The following places are respectively occupied by the Netherlands, Romania, Italy, Greece and Hungary (FAOSTAT). Unfortunately, FAO data do not include Poland in European sweet pepper production. In the European Union, Spain is still the largest producer of sweet peppers. National and world statistics do not provide the area of crops, pepper harvest in individual years at Poland (GUS, 2018). Despite the lack of detailed estimates, it can be concluded that, next to tomatoes and cucumbers, pepper is the third plant covering the largest growing area under shelter in Poland. It is estimated that pepper in unheated tunnels covers an area of about 900-1,000 ha. Similarly to the area of crops, the statistics do not provide the harvest of pepper in individual years and the level of its consumption in Poland. However, the available data shows that the annual production of small-fruit varieties is estimated at approx. 15 thousand tons, while large-fruit varieties from under covers for about 100 thousand tons per year. Polish pepper belongs to the products that are popular on foreign markets. It is estimated that about $30 \%$ of the red sweet pepper produced fresh is exported ${ }^{3}$.

Figure 1 presents the course of time series of red pepper prices on the examined wholesale markets. Vegetable prices

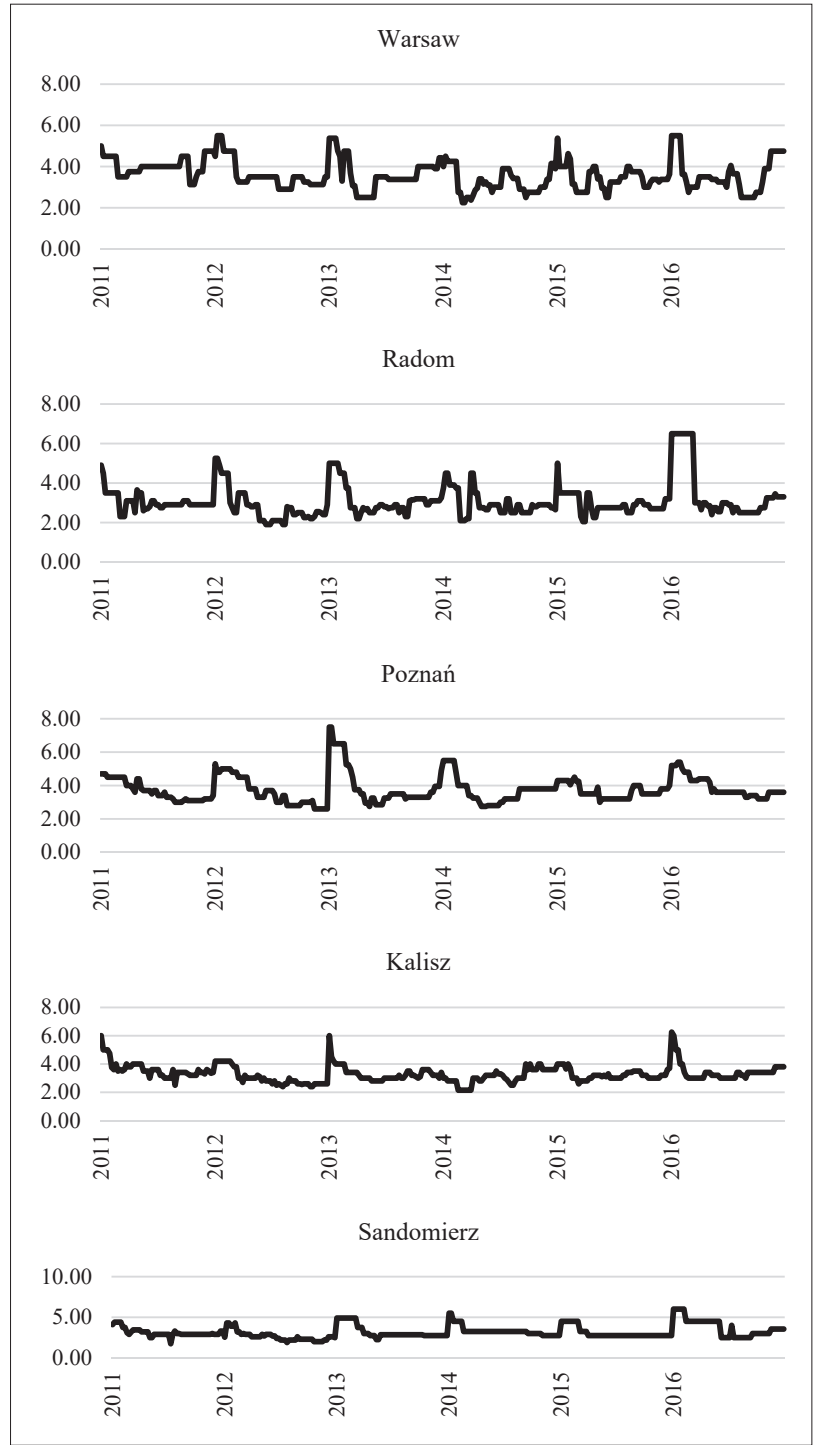

FIGURE 1. Price level of red pepper on wholesale markets in Poland in 2011-2016.

Source: own calculations.

depend to a large extent on the level of supply. This is particularly important in the case of seasonal species such as red pepper. The analysed time series of red pepper prices were characterized by a high level of fluctuation. Variations on the wholesale market in Radom and Sandomierz were characterized by the highest degree of differentiation. It should be noted that it was in these markets throughout the analysed period that the price of red pepper was the lowest. Based on

TABLE 1. Results of stationarity tests of time series of the red pepper prices under consideration.

\begin{tabular}{lllll}
\hline Specification & ADF test & \multicolumn{3}{c}{ Critical value for the a significance level } \\
\cline { 2 - 5 } wholesale markets & statistics & $\mathrm{a}=0.01$ & $\mathrm{~A}=0.05$ & $\mathrm{a}=0.1$ \\
\hline Warsaw & -5.311917 & -3.4526 & -2.8707 & -2.5716 \\
Poznań & -4.137970 & -3.4526 & -2.8707 & -2.5716 \\
Kalisz & -5.377175 & -3.4526 & -2.8707 & -2.5716 \\
Radom & -4.948565 & -3.4526 & -2.8707 & -2.5716 \\
Sandomierz & -4.314603 & -3.4526 & -2.8707 & -2.5716 \\
\hline
\end{tabular}

Source: own calculations using the EViews program.

\footnotetext{
${ }^{3}$ The estimates were based on in-depth interviews among entities operating in the vegetable export sector in Poland and producers of this vegetable.
} 
TABLE 2. Results of Johansen's cointegration tests of the red pepper.

\begin{tabular}{|c|c|c|c|c|c|}
\hline $\begin{array}{l}\text { The number of } \\
\text { cointegrating vectors }\end{array}$ & Eigenvalue & $\lambda_{\text {trace }}$ test & $\begin{array}{c}\text { Critical value for } \\
\qquad a=0.05\end{array}$ & $\lambda_{\max }$ test & $\begin{array}{c}\text { Critical value for } \\
\qquad a=0.05\end{array}$ \\
\hline $0^{*}$ & 0.150820 & 176.9528 & 69.81889 & 52.47841 & 33.87687 \\
\hline $1^{* *}$ & 0.135927 & 124.4744 & 47.85613 & 46.89761 & 27.58434 \\
\hline 2 & 0.099703 & 77.57675 & 29.79707 & 33.71465 & 21.13162 \\
\hline 3 & 0.075190 & 43.86210 & 15.49471 & 25.09171 & 14.26460 \\
\hline 4 & 0.056798 & 18.77039 & 3.841466 & 18.77039 & 3.841466 \\
\hline
\end{tabular}

${ }^{*}$ Means the rejection of $\mathrm{H}_{0}$ at the level of $\mathrm{a}=0.05$.

$H_{0}: \operatorname{rank}(\Pi)=0 ; H_{1}: \operatorname{rank}(\Pi)>0$.

${ }^{* *} \mathrm{H}_{0}$ : $\operatorname{rank}(\Pi)=1 ; \mathrm{H}_{1}: \operatorname{rank}(\Pi)>1$.

Source: own calculations using the EViews program.

TABLE 3. Granger causality test results for red pepper.

\begin{tabular}{|c|c|c|c|c|c|}
\hline Specification & Warsaw & Kalisz & Poznań & Radom & Sandomierz \\
\hline Warsaw (-1) & $\begin{array}{c}\rightarrow \\
(0.0000)\end{array}$ & $\begin{array}{c}\rightarrow \\
(0.04958)\end{array}$ & $\begin{array}{c}\rightarrow \\
(0.07027)\end{array}$ & $\begin{array}{c}X \\
(0.56917)\end{array}$ & $\begin{array}{c}X \\
(0.52795)\end{array}$ \\
\hline Kalisz (-1) & $\begin{array}{c}\rightarrow \\
(0.00372)\end{array}$ & $\overrightarrow{(0.0000)}$ & $\begin{array}{c}X \\
(0.48729)\end{array}$ & $\begin{array}{c}X \\
(0.24854)\end{array}$ & $\begin{array}{c}X \\
(0.15522)\end{array}$ \\
\hline Poznań (-1) & $\begin{array}{c}X \\
(0.86251)\end{array}$ & $\begin{array}{c}X \\
(0.60322)\end{array}$ & $\begin{array}{c}\rightarrow \\
(0.0000)\end{array}$ & $\begin{array}{c}X \\
(0.23192)\end{array}$ & $\begin{array}{c}\rightarrow \\
(0.00567)\end{array}$ \\
\hline Radom (-1) & $\begin{array}{c}X \\
(0.68311)\end{array}$ & $\begin{array}{c}X \\
(0.46679)\end{array}$ & $\begin{array}{c}X \\
(0.95181)\end{array}$ & $\begin{array}{c}\rightarrow \\
(0.0000)\end{array}$ & $\begin{array}{c}\rightarrow \\
(0.03776)\end{array}$ \\
\hline Sandomierz (-1) & $\begin{array}{c}\rightarrow \\
(0.05419)\end{array}$ & $\begin{array}{c}\leftarrow \\
(0.51545)\end{array}$ & $\begin{array}{c}\leftarrow \\
(0.98889)\end{array}$ & $\begin{array}{c}\leftarrow \\
(0.31924)\end{array}$ & $\begin{array}{c}\rightarrow \\
(0.0000)\end{array}$ \\
\hline
\end{tabular}

Value in brackets $-p$ value for the relevant statistics, $X$ - lack of causality, $\leftrightarrow-$ mutual relationship.

$\leftarrow, \rightarrow-$ directions of occurrence of causality in the Granger sense.

Source: calculations and own elaboration using the EViews program.

the analyses carried out, it can be concluded that the most stable wholesale market in the case of red pepper in the years 2011-2016 was the wholesale market in Kalisz. Price volatility in this market was much lower than in the case of other markets.

The interdependence of time series study requires the evaluation of their stationarity. The level of integration of the examined daily quotations of red pepper prices was determined using the extended Dickey-Fuller test (ADF). According to the assumptions of the ADF test, the null hypothesis states that the examined time series are non-stationary. Hence, where the calculated value of the ADF test is lower than the critical value, there is no reason to reject the null hypothesis (about the non-stationarity of a variable). The test results for the analysed time series presented in Table 1 indicate the stationarity of all the variables tested.

In order to use the Johansen test, the VAR(4) above needs to be turned into a vector error correction model (VECM) of the form:

$$
\begin{aligned}
& \Delta y_{t}=\Pi y_{t-k}+\Gamma_{1} \Delta y_{t-1}+\Gamma_{2} \Delta y_{t-2}+\cdots+\Gamma_{k} \Delta y_{t-(k-1)}+\mu_{t} \\
& \text { where } \Pi=\left(\sum_{i=1}^{k} \beta_{i}\right)-I_{g} \text { and } \Gamma_{\mathrm{i}}=\left(\sum_{j=1}^{i} \beta_{j}\right)-I_{g}
\end{aligned}
$$

This VAR contains $g$ variables in first differenced form on the VAR(4) and k-1 lags of the dependent variables (differences), each with $\Gamma$ coefficient matrix attached to it. The Johansen test examinations of the $\Pi$ matrix. $\Pi$ can be inter- preted as a long-run coefficient matrix.

The Johansen cointegration test with the use of the $\lambda_{\text {trace }}$ test and the $\lambda_{\max }$ test confirmed the full column row of the $\Pi$ matrix for the variables under consideration. It should be assumed that the correct form of the model will be the VAR model. The matrix $\Pi=\alpha \beta^{T}$. The matrix $\beta$ gives the cointegrating vectors, $\alpha$ gives the amount of each cointegrating vector entering each equations of the VECM. It is known as the adjustment parameters.

In order to determine the existence of interdependencies in the area of price formation between individual wholesale markets, a causality analysis in the Granger sense was used. The results of the Granger causality test showed that only half of the prices of red pepper on a given market could have caused changes in their level on another market. In addition, these relations were one-way. On the basis of the test, it can be pointed out that price changes on the wholesale market in Poznań and Kalisz were the reason for shaping the price of red pepper on the market in Warsaw and Sandomierz. The prices of the examined variety on the wholesale market in Sandomierz were also influenced by the prices on the market in Radom. In addition to the above, causality in the Granger sense has not been demonstrated in the case of red pepper in the period 2011-2016.

In order to investigate the links between the prices of red peppers on the analysed wholesale markets, the VAR(1) model was used (a further increase in variable delays in the VAR model did not affect the improvement of its statistical 
TABLE 4. Results of the estimation of the VAR(1) model parameters - the price of red pepper.

\begin{tabular}{lllllc}
\hline Specification & Warsaw & Kalisz & Poznań & Radom & Sandomierz \\
\hline Warsaw (-1) & 0.858330 & 0.106963 & 0.109761 & 0.062566 & 0.028903 \\
& $(0.03661)$ & $(0.03459)$ & $(0.03616)$ & $(0.04628)$ & $(0.03921)$ \\
Kalisz (-1) & $(23.4456)$ & $(3.09203)$ & $(3.03529)$ & $(1.35177)$ & $(0.73710)$ \\
& 0.189473 & 0.889306 & 0.039965 & 0.084251 & 0.065307 \\
& $(0.04334)$ & $(0.04096)$ & $(0.04281)$ & $(0.05480)$ & $(0.04642)$ \\
Poznań (-1) & $(4.37148)$ & $(21.7137)$ & $(0.93348)$ & $(1.53751)$ & $(1.40678)$ \\
& 0.015055 & 0.004170 & 0.838889 & 0.018493 & 0.089520 \\
& $(0.03777)$ & $(0.03569)$ & $(0.03731)$ & $(0.04775)$ & $(0.04045)$ \\
Radom (-1) & $(0.39859)$ & $(0.11683)$ & $(22.4854)$ & $(0.38728)$ & $(2.21284)$ \\
& 0.028960 & 0.003556 & 0.014832 & 0.756573 & 0.096854 \\
Sandomierz (-1) & $(0.03510)$ & $(0.03317)$ & $(0.03467)$ & $(0.04438)$ & $(0.03760)$ \\
& $(0.82503)$ & $(0.10720)$ & $(0.42777)$ & $(17.0483)$ & $(2.57612)$ \\
R-squared & -0.084900 & -0.022479 & 0.007984 & 0.053406 & 0.700184 \\
Adj, R-squared & $(0.04088)$ & $(0.03863)$ & $(0.04038)$ & $(0.05169)$ & $(0.04379)$ \\
\hline
\end{tabular}

The parameter estimates highlighted in grey were statistically significant.

Source: own calculations using the EViews program, where (.) standard errors and $t$-statistics by the level of significance $=0.05$.

properties). The estimated parameters of the VAR(1) model suggest that there was a dependency in the years 2011-2016 between the prices on selected wholesale markets. The parameter estimates highlighted in grey in Table 4 were statistically significant, which suggests the existence of red pepper pricing links between selected wholesale markets.

A further increase in variable delays in the VAR model did not affect the improvement of its statistical properties. The value of the adjusted coefficient of determination $\mathrm{R}^{2}$ indicates that the share of the variability in the red pepper prices has been explained by the model ranges from $63 \%$ to $80 \%$ for the selected markets.

\section{Conclusions}

Research into the integration of spatially remote markets results from the theory of price formation. The present research was conducted using dynamic econometric methods to determine the dynamics of price adjustments. Interdependencies between prices of red pepper on five wholesale markets in Poland were examined. The estimated parameters of the VAR model suggest that the price level from the previous day had the greatest importance in shaping the prices in a given market. In addition, the relationship between prices in the following markets was demonstrated: wholesale market in Warsaw - wholesale market in Kalisz; wholesale market in Warsaw - wholesale market in Poznań; wholesale market in Poznań - wholesale market in Sandomierz; wholesale market in Radom - wholesale market in Sandomierz.

The Granger causality test results obtained, confirmed significant price effects between individual wholesale markets. At the same time, the strength and direction of mutual price relations were varied in individual cases. The results indicate that changes in the prices of red peppers on the wholesale market in Poznań and Kalisz influenced the price of red peppers on the wholesale market in Warsaw and in Sandomierz. The above dependences may result from the direction of the goods mass flow and suggest the need to continue research in the identification of phenomena and events in the scope of trade in these goods on these markets. In con- nection with the above, it can be pointed out that wholesale markets in the case of red pepper are not spatially integrated, and price impulses are transferred to a small extent.

Our research confirmed the fact that changes in a given market where more strongly affected by changes in the price in the same market than by in other markets. The lack of integration of red sweet pepper markets may be affected by some barrier in the marketing infrastructure or long distance between markets and different of infrastructure. Which in turn leads to high transport costs, and hinders market integration. However, this aspect was not analysed in this paper due to the limited scope of the data. Research on this scope will be continued in the future. Based on the above findings, some recommendations can be made to improve the red pepper marketing chain in Poland. In the data collection process, there was a lack of information regarding phenomena, events and participants of these events on wholesale markets, which significantly determines the factors affecting the level of integration of wholesale markets in Poland. This problem should be addressed in order to try to create a fully functioning system of registration of information on prices, events and their participants on the wholesale markets of fruit and vegetables. This will make it impossible for producers to make accurate decisions regarding the term and place of sale of vegetables, especially sweet red peppers, whose storage time and the possibility of selling fresh is relatively short.

\section{References}

Borkowski, B., and Krawiec, M. (2009). Price risk on the agricultural raw materials market. In Price Risk Management and Possibilities of Stabilizing the Income of Agricultural Producers - Cognitive and Application Aspects. Multiannual Program Rep. 148, p. 47-82.

Brooks, C. (2012). Introductory Econometrics for Finance. $2^{\text {nd }}$ edn. (Cambridge: Cambridge University Press).

Eviews, IHS Global Inc. Serial number: 10A00XXX.

Fackler, P.L., and Goodwin, B.K. (2001). Spatial price analysis. In 
Handbook of Agricultural Economics, 1b, North-Holland, K. Arrow, and M.D. Intriligator, p. 971-1024. https://doi.org/10.1016/S15740072(01)10025-3.

Food and Agriculture Organization of the United Nations (2019). Statistics, FAOSTAT. www.fao.org/faostat/en/ (accessed August 29, 2019).

Gołębiewski, J., and Sobczak, W. (2017). Wholesale Markets for Fruit and Vegetables (Publishing House SGGW).

Granger, C.W.J. (1969). Investigating causal relations by econometric models and cross-spectral methods. Econometrica 37(3), 424-438. https://doi.org/10.2307/1912791.

GUS (CSO) (2018). Rocznik statystyczny rolnictwa (Statistical Yearbook of Agriculture) (Warszawa: GUS).

Kohls, R.L., and Uhl, J.N. (1998). Marketing of Agricultural Products (Macmillan Publishing Company).

Maddala, G.S. (2008). Introduction Econometrics (Wiley).

Monke, E., and Petzel, T. (1984). Market integration: An application to international trade in cotton. Am. J. Agric. Economics 66(4), 481487. https://doi.org/10.2307/1240927.

Sims, C. (1980). Macroeconomics and Reality. Econometrica 48, 1-48. https://doi.org/10.2307/1912017.

Sobczak, W., Zbyrowski, R., and Borkowski, B. (2018). Spatial integration of vegetable wholesale markets in Poland on the selected example. Acta Sci. Pol. Oeconomia 17(4), 151-158. https://doi. org/10.22630/ASPE.2018.17.4.62.

Tomek, W.G., and Robinson, K.L. (2001). Setting of Prices of Agricultural Products (PWN Scientific Publishers).

Received: Sep. 30, 2018

Accepted: Nov. 21, 2019

Addresses of authors:

Wioleta Sobczak ${ }^{1, *}$, Rafał Zbyrowski ${ }^{2}$, Bolesław Borkowski ${ }^{1}$ and Jarosław Gołębiewski ${ }^{1}$

${ }^{1}$ Warsaw University of Life Sciences, Institute of Economics and Finance, Warsaw, Poland

${ }^{2}$ University of Warsaw, Faculty of Management, Warsaw, Poland

* Corresponding author;

E-mail: wioleta_sobczak@sggw.edu.pl 